\title{
A mindtool-based collaborative learning approach to enhancing students' innovative performance in management courses
}

\author{
Chih-Hsiang Wu \\ National University of Tainan, Taiwan \\ Gwo-Jen Hwang \\ National Taiwan University of Science and Technology, Taiwan \\ Fan-Ray Kuo \\ National Sun Yat-Sen University, Taiwan \\ Iwen Huang \\ National University of Tainan, Taiwan
}

\begin{abstract}
Educators have indicated that creative teaching is the most important educational activity; nevertheless, most existing education systems fail to engage students in effective creative tasks. To address this issue, this study proposes a mind map based collaborative learning approach for supporting creative learning activities and enhancing students' innovative performance. An experiment has been conducted on a university management course to evaluate the effectiveness of the proposed method. The experimental results show that the proposed approach significantly enhanced the students' innovative performance in a project-based learning task. Such a finding not only provides evidence of the cultivability of innovative thinking, but also good references for those researchers who are interested in conducting creative learning activities.
\end{abstract}

\section{Introduction}

Creativity is currently one of the key focuses of education reform around the world (Yeh \& Wu, 2006). Many advanced countries are paying more attention to inspiring students' creativity in a variety of different ways. In Taiwan, the Ministry of Education (2003) issued the White Paper on Creative Education in which creativity was integrated into the curriculum, declaring that Taiwan has entered a new era of education for fostering creativity.

Sternberg and Lubart (1999) indicated that creativity is a complex and multifaceted concept, which refers to a process, "a way of thinking, reacting, and working in an imaginative and idiosyncratic way which is characterized by a high degree of innovation and originality, divergent thinking and risk taking." Isaksen and Parnes (1985) asserted that creativity is often context dependent and subject specific; that is, an engineer tends to characterize creativity differently from an artist, a lawyer or a planner. In business management, creativity is seen as being vital for the development of new enterprises and innovation, while in the sciences, creativity is regarded as a means of solving complex problems. It can be developed using a systematic approach, such as through creative thinking instruction and creative problem solving approaches. Creative thinking instruction creates a learning context for students to cultivate underlying abilities such as originality, flexibility, fluency and elaboration, based on their imagination. Ayan and Rick (1997) indicated that Mindtools allow learners to express and share their ideas with others using images, lines and links, which facilitate understanding more easily than using characters and signs. Thus, they also argue that Mindtools such as concept maps or mind maps can be used to stimulate cognition, by enhancing satisfaction and feelings of self-efficacy, or by stimulating meta-cognition and creativity (Kao, Lin, \& Sun, 2008; Shaw, 2010).

Innovation refers to "make something new" (Tidd, Bessant, \& Pavitt, 1997). Enhancing students' innovative performance is related to engaging them in such learning tasks that aim to create something different from what already exists (Baron, 2010). Therefore, creativity is a core component of innovative activity. The occurrence of innovations depends on the accomplishment of creativity; and the value of creativity relies on the presentation of innovation (Ministry of Education, 2003). Consequently, innovation is seen as a critical competence required for business planning, and is more important than 
ever before in the workplace. With the rapid pace of change throughout this decade, enterprises need to face the fact that many traditional thoughts or ways of doing things no longer work. This means that it is essential to have employees in the organization come up with innovative and effective solutions of which their competitors have not thought (LaBarre, 1996). Some empirical studies have indicated that more competitive companies rely on a group of creative employees in a collaborative workplace (Carrier, 1998; Dijk \& Ende, 2002; Delgado-Téllez \& Pérez Raposo, 2011). Accordingly, universities play an important role in preparing students with creative abilities who are able to work in a collaborative environment before entering the workplace. Previous studies have found that mind mapping can be successfully applied to collaborative learning strategies, resulting in better cognitive structures and creative thinking performance than conventional methods (Hwang, Shi, \& Chu, 2011; Torrance, 1970). Skemp (1979) found that students' innovation concepts can be inspired by social interactions as a result of team work, while Davidson and O'Leary (1990) asserted that collaborative learning could develop students' divergent thinking and learning motivation, which are both related to creativity.

According to a review of the research conducted by Alexander (2011), nearly half (48\%) of college students worldwide possess smart phones in which mind mapping tools can be embedded; moreover, most of the students are inclined to use technologies for academic purposes. Despite this, few studies have investigated the effect of mind mapping tools embedded in mobile devices. Thus, this study attempts to investigate the effect of mobile-oriented mind mapping strategies on students' innovative performance in a university undergraduate business planning course. Accordingly, the study proposes an approach which integrates a collaborative mechanism and mind mapping techniques in a mobile learning environment to foster university students' creativity. To assess the effectiveness of the proposed method, a business planning course was conducted in the study to address the following issues:

1. Does the proposed approach improve students' innovative performance in the business planning course?

2. Does the proposed approach improve students' achievement in the business planning course?

3. Do the students accept the adoption of the proposed approach in the mobile learning environment?

\section{Literature review}

\section{Creativity Thinking Instruction}

Mayer (1999) addressed the characteristics of creativity, including originality, innovation, usefulness and appropriation. That is, the performance of creativity depends on the presentation of originality, innovation, usefulness and appropriation. Creative teaching aims to empower teachers and learners to break through fixed moulds and establish innovative cognitive structures in order to transform concepts and ideas into actions (Ke, 2004). Sawyer (2006) further asserted that creative teaching is the most important educational activity.

According to the structure of intelligence, thinking can be considered from two aspects, convergent thinking and divergent thinking (Guilford, 1957). Convergent thinking means the ability to deduce a single possible best solution to a problem, while divergent thinking indicates the ability to generate multiple solutions to a problem. Divergent thinking is regarded as a major aspect of creativity for predicting individual performance (McCrae, 1987).

Guilford (1957) asserts that there are many characteristics of creativity, including high sensitivity to questions, fluency of concepts, curiosity about concepts, flexibility of thinking, ability of integration, ability of analysis, complexity of concept structure, and ability of evaluation. He also believes that creativity is a continuous statistical distribution, such that, one way or another, we all possess some degree of creativity, and that these individual differences can be measured. Csikszentmihalyi (1997) asserts that creativity must be defined in terms of the individual, the learning community and the symbol system together in context. Amabile (1996) proposed a componential model of creativity from the view of product, while from the perspective of individual creativity, the influential factors include domainrelevant skills, creativity-relevant skills and task motivation. Amabile (1997a, 1997b) affirmed that creativity consists of a combination of personal features, cognitive ability and social context. Thus, personal performance in creativity can be evaluated based on the theory of creativity in context, including expertise, creativity skills and task motivation. The more interaction there is among these contributing components, the greater the individual's creativity is. 
As a whole, researchers have proposed a number of different definitions of creativity. In this study, we consider creativity as a trained thinking ability based on the perspectives of a number of the educators (e.g., Komarik \& Brutenicova, 2003; Garaigordobil, 2006). That is, it is necessary to create a context which continually encourages students in both divergent and convergent thinking.

Robinson (2011) indicated that everyone has great abilities but not everyone develops them. One of the problems is that the existing education systems do not provide an effective learning environment to enable students to develop their creative powers. Instead, most education systems promote uniformity and standardization. As a consequence, people are drained of their creative possibilities (Fishkin \& Johnson, 1998; Robinson, 2006). Therefore, how to promote students' potentials of creativity development through creative thinking instruction is very important to students in the current education systems (Sternberg \& Lubart, 1999). Several researchers have pointed out that creativity is not innate, but can be cultivated through proper training (Kurtzberg \& Reale, 1999; Antonietti, 2000; Komarik \& Brutenicova, 2003; Garaigordobil, 2006).

Scholars have further indicated that creative thinking instruction can not only facilitate students' motivation in learning, but can also develop their creative thinking ability (Antonietti, 2000; Komarik \& Brutenicova, 2003; Garaigordobil, 2006). David (1986) pointed out that creative thinking instruction could foster students to become creative people by helping them understand the theme of creativity and by involving them in creative activities and creative thinking processes. Via creative thinking instruction and practice, students' creative characteristics and skills can be strengthened. For example, Clements (1987) proposed a study to investigate the effects of Logo programming and CAI problem-solving software on problem solving performance. The research findings showed that the Logo group had significantly more improvement than the CAI and control groups. Moreover, Clements (1991) investigated the effect of Logo programming on students' creativity in a programming environment, and found that the Logo group significantly outperformed the control group on an assessment of verbal creativity. These results support that Logo enhanced not just the students' figural knowledge, but also the processes involved in creative thought.

Parnes (1967) further asserted that creativity could be trained via a series of learning activities; for example, brainstorming is a group creativity technique that engages a group of people in finding creative and possible solutions to a specific problem by gathering a list of ideas (Putman \& Paulus, 2009; Gallupe et al., 1992).

As mentioned previously, creative thinking ability can be enhanced via a systematic program in which students' high-order thinking skills and intelligence structure are developed (Chiu, 2009; Wright \& Fesler, 1990). During the learning process, educators should apply any possible instruction strategy to inspire students' creative thinking ability (de Jesus, de Souza, Teixeira-Dias, \& Watts, 2005).

\section{Creativity and collaborative learning}

The term "collaborative learning" refers to an instruction method in which students at various performance levels work together in small groups toward a common goal (Thousand, Villa, \& Nevin, 2002; Chiu, 2008; Mitnik, Recabarren, Nussbaum, \& Soto, 2009). The students are responsible for one another's learning as well as their own. Thus, the success of one student helps others to be successful. Fostering creativity is increasingly seen as a key direction and focus for pedagogic approaches from nursery education through the compulsory years to higher education and work-based environments (Cheng, 2009; Glor, 1998). Amabile (1996) indicated that individual creativity is able to be mediated by the group and to be supported by the social environment and management. Collaborative support can foster students' creative thinking and problem solving through the process of intensive interaction, reflection and the collaboration of participants (Delgado-Téllez \& Pérez Raposo, 2011; Yang \& Cheng, 2010; Baloche, 1994; Peters \& Torrance, 1972; Torrance, 1970, 1971).

Delgado-Téllez and Pérez Raposo (2011) proposed a collaborative learning scenario for university students to solve architectural problems. Their research findings showed that in such a learning scenario, students are able to learn innovative solutions through collective brainstorming processes. Baloche (1994) conducted an elementary music education program designed to encourage creativity and cooperative 
learning among students. The results indicated that the elementary music teachers involved were able to adapt cooperative-learning models which influenced the students' creativity and attitudes toward cooperation.

Several studies have indicated that creativity has significant correlation with collaboration (DelgadoTéllez \& Pérez Raposo, 2011; Yang \& Cheng, 2010; Turnbull, Littlejohn, \& Allan, 2010; Cheng, 2009); for example, Carroll, Latulipe, Fung, and Terry (2009) proposed a standardized survey metric, the Creativity Support Index (CSI), to help researchers and designers evaluate students' creativity levels. They reported that collaboration could be a strong component in creativity factor evaluation. Thus, in this study, we propose a collaborative learning approach using Mindtools in the learning context.

Parker and Chao (2007) conducted a collaborative learning activity in which Wiki was used as a web communication and collaboration environment to engage students in innovative thinking tasks. Klein and Letaief (2005) found that collaboration is an important element to facilitate innovative thinking of elementary school students in a creative Art course. They indicated that the collaborative platform needs to facilitate asynchronous systematic conceptions and sharing of intra- and cross-organizational information such that students are situated in a synergistic, creative and innovative learning environment.

\section{Mindtools}

Mindtools are computer applications that necessarily engage learners in thinking about the content they are studying when they are used to represent what the learners know (Jonassen, 1996). In past decades, graphical Mindtools have been widely employed in educational settings. Most graphical Mindtools, such as Inspiration, are commercial products. In this study, the mind mapping tool that was adopted for conducting the creative learning tasks was selected for several reasons. First, it is shareware, which is important for schools and students who cannot afford to purchase commercial products. Second, it provides user interfaces in several languages, including Chinese. Third, it provides a facility to rearrange the layout of the nodes and corresponding links created by the learners, which is very helpful to students in presenting their ideas during the creative and innovative thinking process since they do not need to worry about the appearance of the mind maps. In addition, these mind mapping tools have been adopted by researchers for making business plans of enterprises via the brainstorming process (Lanchwathanakorn, 2011; Liu, Lin, Jian, \& Liou, 2012). Therefore, we aimed to propose a mind map-based collaborative learning approach to facilitate the students' creative and innovative thinking in a project-based learning task.

Mind mapping or mind maps were proposed by Tony Buzan in the early 1970s, and are by definition a graphical method of taking notes. Their visual basis helps one to distinguish words or ideas, often with colours and symbols. They generally take a hierarchical or tree branch format, with ideas branching into their subsections. Mind maps allow for greater creativity when recording ideas and information, as well as allowing the note-taker to associate words with visual representations, such as colours, pictures, codes, lines and keywords (Buzan, 2000; Kurtzberg \& Reale, 1999). Sketching a mind map entails the following six steps: (1) Begin in the middle of the blank web page, composing or drawing the idea you want to produce; (2) Develop the actual related subtopics for this central subject, connecting all of them to the centre with a line; (3) Repeat the same process for the subtopics, generating lower-level subtopics as you see a match, connecting each one to the corresponding subtopic; (4) Make copious use of colour, sketches and symbols; (5) Keep the topic labels as short as possible, keeping all of them to an individual term, or to merely an image; (6) Alter the text dimensions, colours and alignment as required.

Mind mapping has many applications in personal, family, educational, and business situations, including note taking, brainstorming (wherein ideas are inserted into the map radially around the centre node, without the implicit prioritization that comes from hierarchical or sequential arrangements, and wherein grouping and organizing is reserved for later stages), summarizing, as a mnemonic technique, or to sort out a complicated idea. Mind maps are also promoted as a way of collaborating in colour pen creativity sessions. Mind maps can be employed for problem solving, framework design, individual expression of creativity, team building or synergy creating activities (Wycoff \& Richardson, 1995). Mind mapping is thus one kind of divergent thinking tool which could be applied in brainstorming and association as in Buzan's (2000) experiment of brainstorming about the concept of "Happiness," as shown in Figure 1. Such a method is called "Brain Flow." The result revealed that those involved in the process came up with 
different terms related to happiness, implying that they all had different associations with that specific theme. Moreover, the same results were achieved for different themes, indicating that few people have the same connections with the same term. Thus, mind maps could help people to promote their intellectual brainstorming and association skills (Buzan \& Buzan, 2006).

Creativity experts Ayan and Rick (1997) indicated that mind mapping can stimulate visual intelligence because many people have a greater sense of visual information if they can express their ideas with images. Through such a process, they can easily understand the relationship among the concepts such that they can naturally extend their thinking scope and spatial concepts (Buzan \& Buzan, 2006).

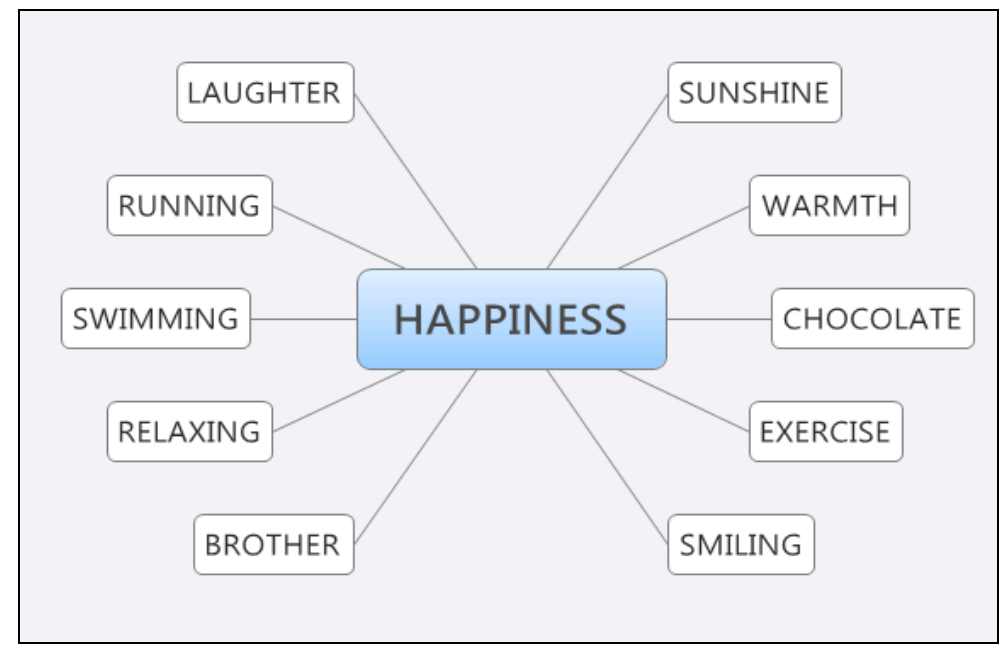

Figure 1. Illustrative example of a mind map of "Happiness".

\section{Research method}

\section{Participants}

In this study, three classes constituting a total of 137 students taking an undergraduate Business Planning course at a university in northern Taiwan were assigned to three groups. Experimental group one included 44 students who adopted a mobile-based Mindtools application embedded in mobile devices with a collaborative learning approach; experimental group two included 47 students who adopted computerbased Mindtools with a collaborative learning approach but did not use mobile devices; the control group included 46 students who adopted a conventional collaborative learning approach with neither the use of Mindtools nor mobile technology. To avoid the Hawthorne Effect, the students in the three groups were not aware of their roles in the experiment. Moreover, when choosing the participating classes, the physical locations of the classes were taken into account; that is, non-adjacent classes were chosen to avoid the students from different classes influencing each other.

\section{Experimental procedure}

The experimental procedure of the study is shown in Figure 2. The subject of the study was a unit called "Business Planning and Proposal Practice," in which the students needed to work collaboratively to develop a business plan. Experimental group one conducted their planning with mobile-based Mindtools using a collaborative mind mapping approach, experimental group two was assigned to conduct their planning process using computer-based Mindtools with collaborative mind mapping, while the control group adopted the conventional computer-supported collaborative learning approach. In the first week of learning activities, experimental group one was taught to use the mobile Mindtool-based software and was taught about creative thinking, experimental group two was taught the computer Mindtool-based software and creative thinking, and the control group was taught about creative thinking. Afterwards the three groups worked on six themes of creative thinking learning activities over a period of six weeks, including such themes as food and $3 \mathrm{C}$ products. This six week intervention trained the students' creative 
ability and business planning skills, as well as allowing the two experimental groups to become familiar with operating the Mindtools software.

In the last week, the students in each of the three groups were required to complete a final business plan and proposal project as a posttest. The final project topic was entitled 'Laptop Products,' and was related to an exhibition of computers and information technology.

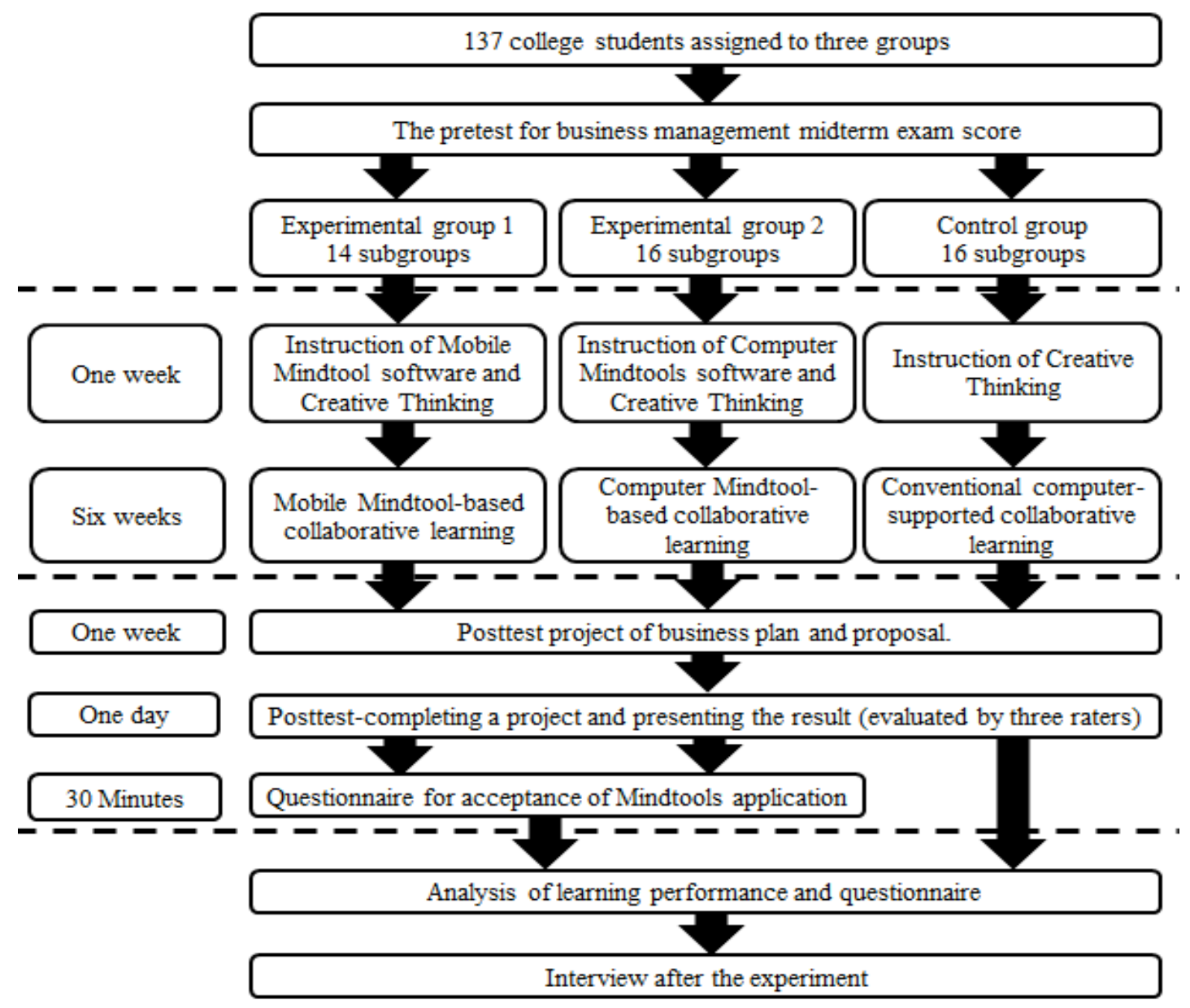

Figure 2. Experimental procedure of the study.

After the learning activities, the students were required to develop a business plan and proposal as the posttest. During the learning process, the students in experimental group one employed mobile phones to execute the Mindtool, as shown in Figure 3. On the other hand, Experimental group two used the "XMind" computer-based Mindtools, as shown in Figure 4. 

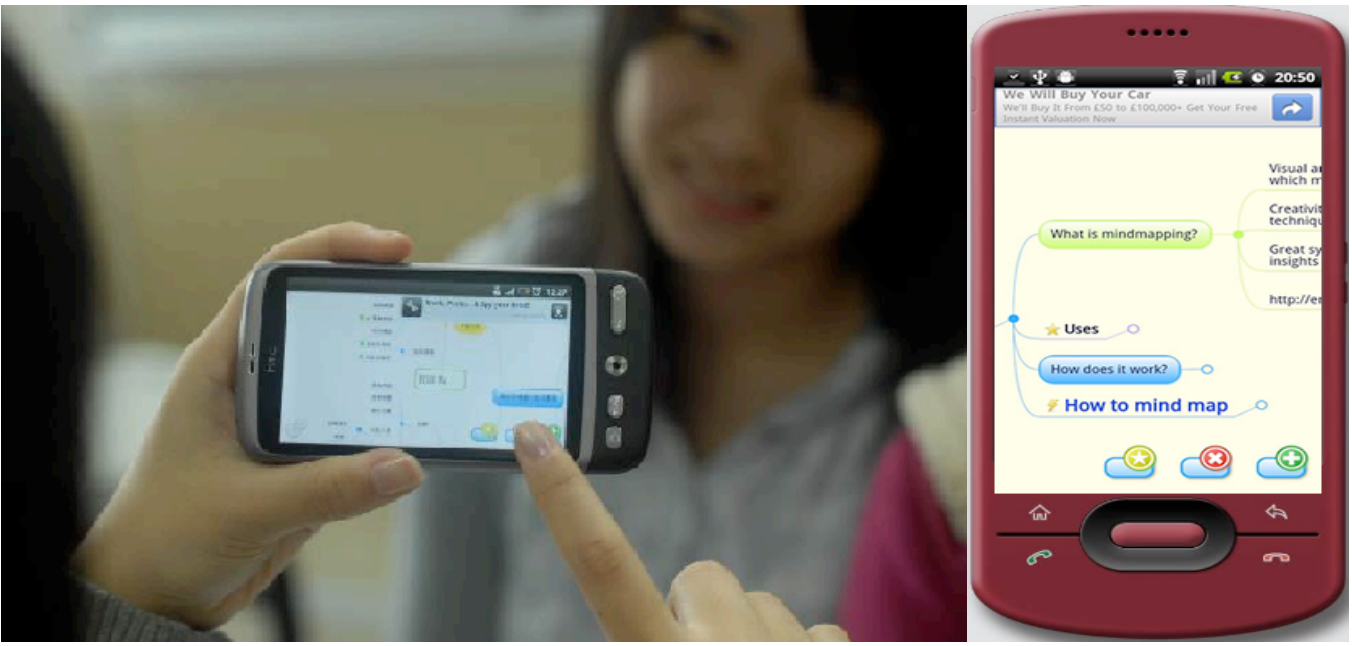

Figure 3. Interface of the Mindtool "Mindjet" for mobile phones.

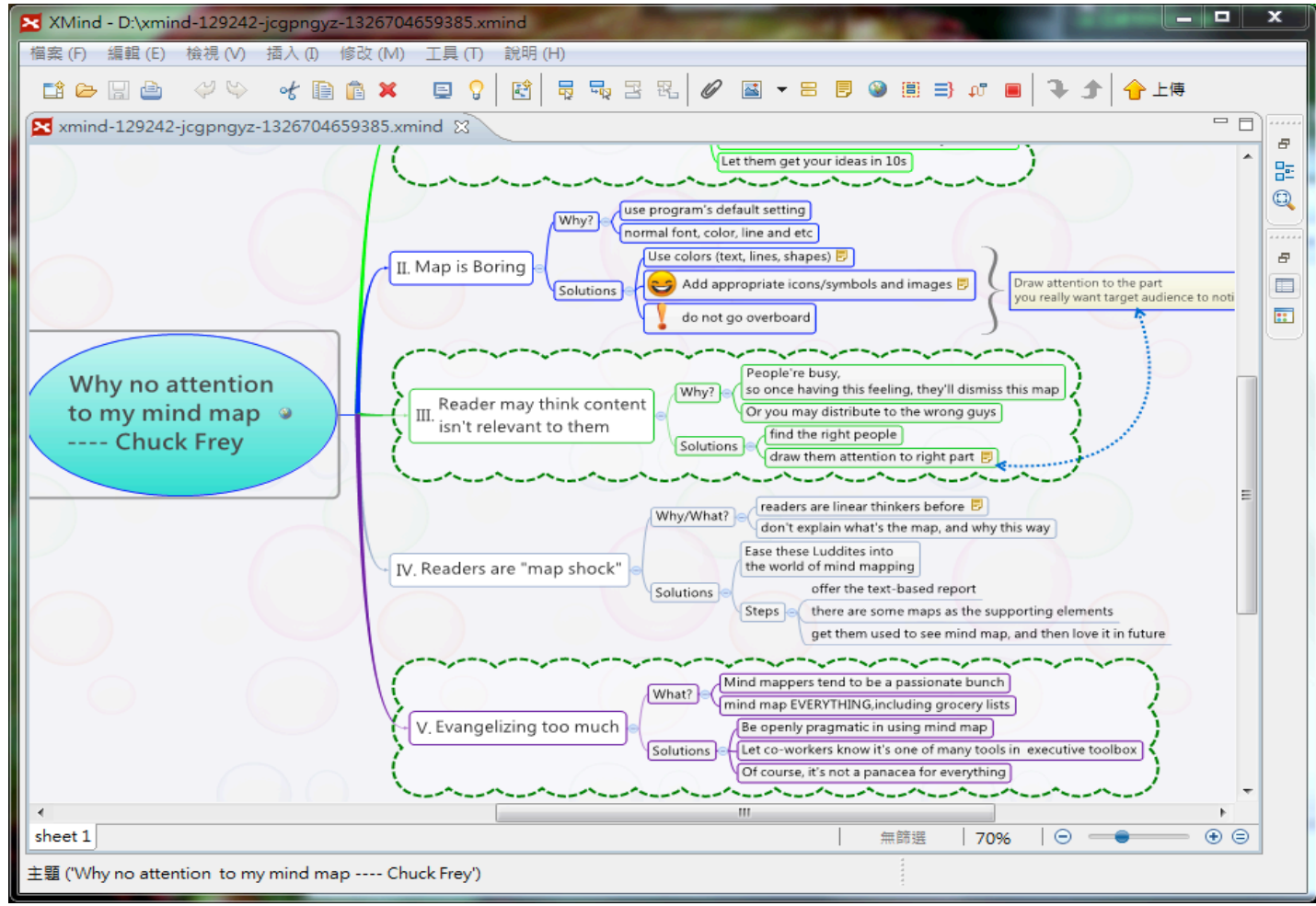

Figure 4. Interface of computer-based Mindtool "XMind".

During the learning activity, the students could come up with any idea divergently based on a theme via the mind mapping tool. Through convergent thinking processes, the students could find possible solutions related to the theme. Moreover, the mind maps allowed individual students to think creatively with simple graphics and a brief text description so that their peers were able to grasp their ideas. Thus, members of each sub-group were able to complete their mind maps collaboratively. An example of a finalized mind map for a business plan is given in Figure 5, which was developed via a collaborative learning group using Mindtools. 


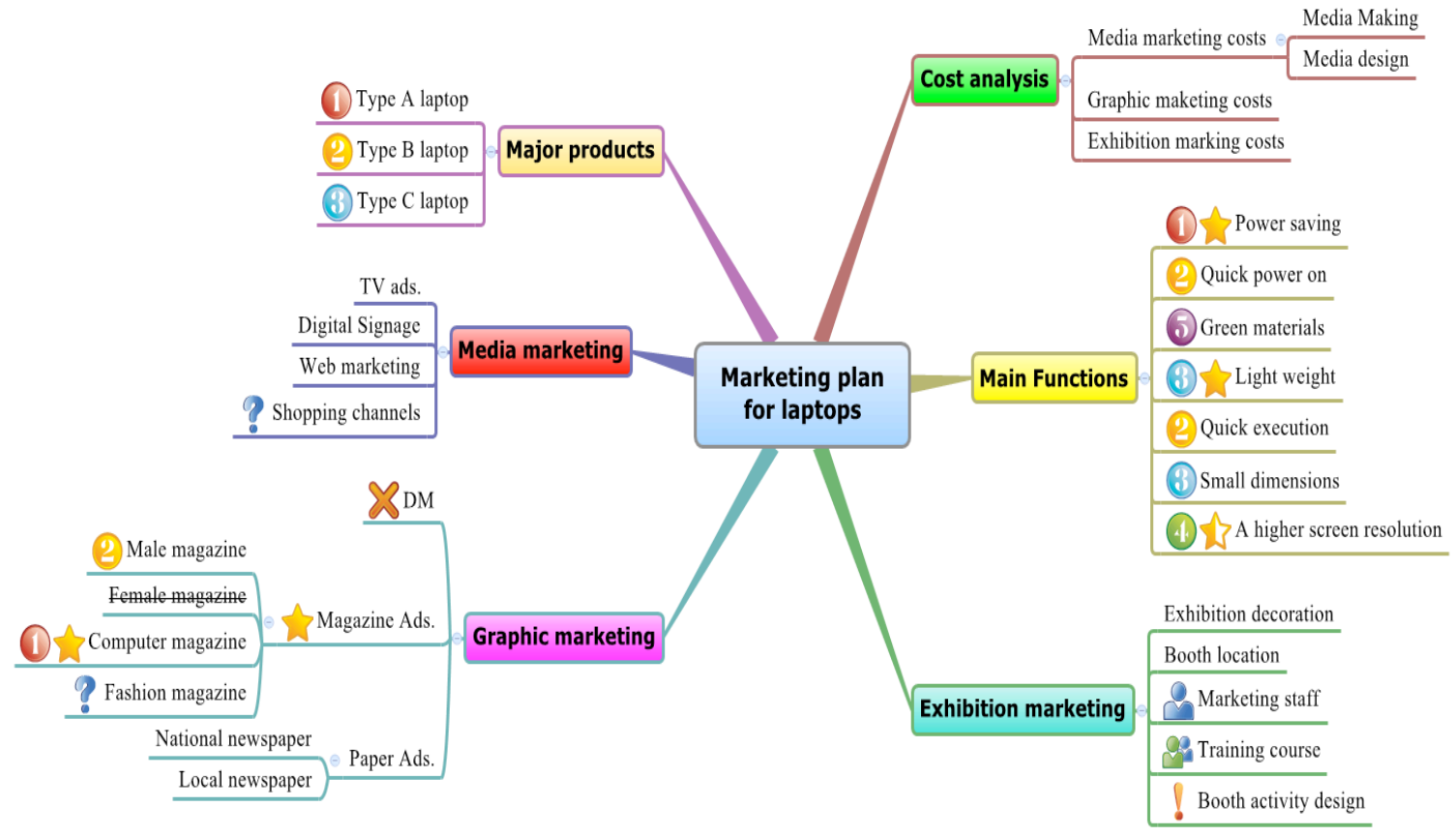

Figure 5. Screenshot of one sub-group's finalized mind map.

\section{Measuring tools}

The assessment of the business plans was carried out by three experts with over five years' experience of teaching the business course. The criteria of the assessment related to how the students developed their business plans based on three dimensions, creativity, completeness and oral presentation. Before conducting the assessment, one non-experimental group with 14 students participated in the pretest to evaluate the validity of the assessment. Meanwhile, the rating rules were defined according to open-ended questions about the business plans. The score of the business plans was based on three aspects: (1) innovation, which refers to the number of innovations in the plan, with a score ranging from 0 to $60 ;(2)$ completeness, which was evaluated based on the structure of the plan, with a score ranging from 0 to 20 , and (3) oral presentation skills, which was evaluated based on the students' presentation of their plans, with a score ranging from 0 to 20 (Miner \& Miner, 2008; Ward, 2011) .

The three experts were invited to evaluate the business project, and their average scores represented the score for each student. The pretest result was analyzed with Pearson correlation analysis. The correlation coefficient of the three raters was between 0.77 and 0.890 , implying that there was high inter-rater reliability in the evaluation of the students' proposal planning performance (Cohen, 1988; Bryman \& Cramer, 1997), as shown in Table 1.

Table 1

Pearson correlation analysis for the three raters $(N=14)$

\begin{tabular}{cccc}
\hline & Rater 1 & Rater 2 & Rater 3 \\
\hline Rater 1 & 1 & & \\
Rater 2 & $0.805 * * *$ & 1 & \\
Rater 3 & $0.770^{* *}$ & $0.890^{* * *}$ & 1 \\
\hline Note. $* * p<.01, * * * p<.001$ & &
\end{tabular}

In addition, to measure the students' acceptance of the mind mapping strategy, an acceptance questionnaire originating from the questionnaire developed by Chu, Hwang, Tsai, and Tseng (2010) was administered. It was constructed and validated by the researchers and two experts and consists of 20 
items with a five-point Likert rating scheme, including 10 items for "Perceived usefulness," numbered 110, and 10 items for "Perceived ease of use," numbered 11-20. This questionnaire was administered to the two experimental groups during the posttest phase after the groups had completed the experiment. The Cronbach's alphas of the two dimensions are 0.807 and 0.801 , respectively, and the Cronbach's alpha of the entire acceptance questionnaire reaches 0.859 , which shows high internal consistency and reliability of the scale (Cohen, 1988; Bryman \& Cramer, 1997).

In addition to the quantitative analysis, a qualitative method was employed after the experiment. Several interview questions were used to obtain the students' perceptions of using the mind mapping tool in the learning context, such as "Do you encounter any difficulties when using the mind mapping tool during the learning process?", "Is the mind mapping tool helpful to you in terms of group discussions during the learning activity?" and "Can the mind mapping tool improve your performance in completing the business plan?"

\section{Results and Discussions}

\section{Analysis of learning achievement}

After the business plans were completed, the three raters were required to evaluate each group's plan, and the total score for each group was the sum of the three raters' scores. A homogeneity of variance test was conducted first before the ANOVA test, and revealed that the three groups' test scores did not reach significance level $(\mathrm{F}=0.528, p=0.594>0.05)$, implying that the abilities of the students in the three groups were equivalent prior to the intervention, which meets the basic assumptions of ANOVA. Then, ANOVA was conducted to analyse the students' business plan achievements in terms of the dimensions of "innovation," "completeness," "oral presentation skills" and "total score," as shown in Table 2. The test results in Table 2 show that the scores of the two experimental groups are significantly superior to those of the control group $(\mathrm{F}=5.50, p<.01)$, implying that the mind mapping mechanism embedded in the learning activity was definitely beneficial to the experimental group students. Further investigation of the influence of the different dimensions found that for the dimension of innovation, the two experimental groups had significantly better scores than the control group $(\mathrm{F}=4.69, p<.01)$, implying that the mind mapping mechanism was helpful to the experimental group students in terms of their creative thinking ability. That is, the mind mapping tool allowed the students to experience divergent creative thinking by drawing, and also allowed them to come up with convergent ideas via the use of graphic representations. Such a thinking process could help the experimental group students' ideas converge into a single direction for their business plans. Moreover, creativity could be the determinant when developing the success of a business plan (Miner \& Miner, 2008). Thus, the result shows that the intervention of the mind mapping mechanism was helpful to the students in developing their plans.

Table 2

ANOVA of the post-test for the three groups

\begin{tabular}{lllllll}
\hline & \multicolumn{1}{c}{ Group } & N & Mean & S.D. & F & Post hoc \\
\hline \multirow{2}{*}{ Innovation } & (1) Experimental Group 1 & 14 & 48.14 & 5.20 & $4.69^{* *}$ & $(1)>(3)$ \\
$(60 \%)$ & (2) Experimental Group 2 & 16 & 45.94 & 4.95 & & $(2)>(3)$ \\
& (3) Control Group & 16 & 41.75 & 5.95 & & \\
Completeness & (1) Experimental Group 1 & 14 & 16.79 & 1.63 & 1.54 & \\
$(20 \%)$ & (2) Experimental Group 2 & 16 & 16.56 & 1.03 & & \\
& (3) Control Group & 16 & 15.81 & 1.11 & & \\
Oral presentation & (1) Experimental Group 1 & 14 & 15.43 & 1.50 & 0.60 & \\
skills (20\%) & (2) Experimental Group 2 & 16 & 15.69 & 1.20 & & \\
& (3) Control Group & 16 & 15.70 & 1.12 & & \\
Total score & (1) Experimental Group 1 & 14 & 80.43 & 6.90 & $5.50^{* *}$ & $(1)>(3)$ \\
& (2) Experimental Group 2 & 16 & 78.13 & 5.61 & & $(2)>(3)$ \\
& (3) Control Group & 16 & 73.75 & 5.85 & & \\
\hline
\end{tabular}

Note. ${ }^{* *} p<.01$ 
In contrast, the students in the control group adopted a text-based thinking approach, which easily led to misconceptions, and made it difficult to grasp the theme and the ideas of creative thinking. Accordingly, they were unable to effectively develop creative thinking ability (Wycoff \& Richardson, 1995; Amabile, 1996). Through interviews with some of the students from the two experimental groups, the students of experimental group one expressed that they could easily discuss and draw mind maps with each other via their mobile phones in their spare time, while the students in experimental group two thought they could not discuss or draw mind maps with each other unless the computer classroom was available for use during their spare time.

\section{Analysis of acceptance of mind mapping}

In order to investigate the acceptance of the mind mapping mechanism by the two experimental groups, a questionnaire of acceptance of mind mapping in business planning was conducted after the learning activity.

The first dimension of the questionnaire is the perceived usefulness of the mind mapping mechanism, which attempts to investigate the students' perceived usefulness level of adopting the mind mapping mechanism in learning business planning. We found that the mean scores of perceived usefulness of the two experimental groups were 4.11 and 4.07 , respectively. This indicates that the students in both experimental groups believed that the mind mapping mechanism embedded in the learning activity was useful for their learning performance. A further investigation revealed that the students in the two experimental groups also agreed that mind mapping embedded in business planning could help them concentrate on the topic and reorganize their shared knowledge; moreover, it helped them promote their creative thinking ability and come up with more ideas when making a business plan. This finding is consistent with that of a previous study reported by Miner and Miner (2008) that creative thinking ability is an important determinant for students to make a successful business planning case. Furthermore, the students of both experimental groups indicated that the mind mapping mechanism could help them increase their interaction with their group members, and share ideas with each other easily when making a business plan together. Such a learning context could effectively improve students' discussion content via the use of visual graphics. The students further suggested that mind mapping tools could be used in more disciplines relating to memory, creativity and logistics (Gentner, Anggoro, \& Klibanoff, 2011; Liu, Chen, \& Chang, 2010; Ismail, Ngah, \& Umar, 2010).

The second dimension of the questionnaire is perceived ease of use of mind mapping in business planning. The higher the score, the easier the students perceive the use of the mechanism to be. The mean scores of perceived ease of use of the two groups are 3.44 and 3.68, indicating that most of the students tend to agree that the mind mapping mechanism was easy to use in the learning activity.

Table 3 shows the independent sample t-test of two questionnaire items to which the two experimental groups showed significantly different responses. We found that the mind mapping mechanism embedded in the computer-based learning activity was easier to use than that embedded in the mobile-based learning activity; however, using mobile devices was more helpful to the students in terms of completing the business plan.

An interview was further conducted to investigate the reasons for this finding. According to the feedback of the experimental group one students, it is difficult to revise the contents of the mind maps using the small screen of the mobile devices. Moreover, it is also unfriendly for them to input text via handwriting or the onscreen keyboard functions. On the other hand, the students in experimental group two indicated that using personal computers to develop business plans made them difficult to discuss, showing that the need for face-to-face discussions was met by using the mobile devices. Accordingly, it would be worthwhile for educational institutes to consider adopting mobile devices with larger screen sizes, such as e-books, in the future. 
Table 3

Independent sample t-test of acceptance of the mind mapping mechanism for the two experimental groups

\begin{tabular}{lccccc}
\hline \multicolumn{1}{c}{ Question } & Group & N & Mean & SD. & t \\
\hline It is easy to complete the mind map with & Exp. Group 1 & 44 & 3.98 & 0.82 & $-2.89^{* *}$ \\
this learning approach. & Exp. Group 2 & 47 & 3.53 & 1.00 & \\
& Exp. Group 1 & 44 & 3.14 & 0.96 & $-2.11^{*}$ \\
I think it is easy to revise the mind map. & Exp. Group 2 & 47 & 3.55 & 0.93 & \\
\hline
\end{tabular}

Note. ${ }^{*} p<.05, * * p<.01$

\section{Conclusions and suggestions}

In this study, a collaborative mind mapping approach for supporting creative learning activities is proposed; moreover, an experiment on a management course of a university has been conducted to evaluate the effectiveness of the proposed approach on different computer platforms. The experimental results show that both groups of students who learned with the collaborative mind mapping mechanism via mobile devices and desktop computers had significantly better performance than those who learned with the conventional instruction, implying that the use of Mindtools in collaborative learning activities was able to improve the creativity of the students, no matter which kind of computer platform was used.

This result is consistent with previous findings (Ismail, Ngah, \& Umar, 2010; Buzan \& Buzan, 2006; Ayan \& Rick, 1997). However, the two experimental groups had no significant difference in the posttest of learning achievement, although the mean score (48.14) of experimental group one was greater than that (45.94) of experimental group two. Interviews were conducted to further investigate the reasons, and it was found that some students of experimental group one found that the mobile-based Mindtools were able to help them discuss their plans and draw their mind maps anytime and anywhere. Comparatively, the students of experimental group two were able to manipulate the computer-based Mindtools and discuss their mind maps only in the computer classroom at specific times. Thus, this result is consistent with previous research findings concerning the advantages of mobile learning (Hwang \& Chang, 2011; Hwang, Wu, \& Ke, 2011; Looi et al., 2010; Uzunboylu, Cavus, \& Ercag, 2009) and Bandura's social cognitive theory (Bandura, 1976), indicating that an individual's knowledge can be directly constructed by observing others within the context of social interaction.

In addition, from the questionnaire of acceptance of the mind mapping mechanism, we found that most of the students in the two experimental groups tended to agree that the mind mapping mechanism was beneficial in the development of their business plans in terms of the dimension of "perceived usefulness." However, for the dimension of "perceived ease of use," the students in experimental group two reported significantly higher scores than those in experimental group one in terms of the learning system interface. Although the mobile-based Mindtool approach benefited the students in this application, the small screen size of the mobile devices restricted the display and editing of the mind maps; consequently, it is suggested that instructors need to take the number of nodes in the mind maps into consideration when designing a learning task. Moreover, the use of more contemporary mobile devices with bigger screens and easy-to-use interfaces, such as Apple's iPad or Tablet PCs, could be a solution to address this problem. Furthermore, it might extend the possibilities of conducting online real-time forums and knowledgesharing platforms in the current project, which would engage students in a more interactive and meaningful manner.

In the future, several extended studies can be considered; for example, the investigation of the effects of individual differences (e.g., gender or achievement level) on students' creative performance in a technology-enhanced learning environment with Mindtools. In particular, several researchers have emphasized the importance of investigating gender differences in e-learning studies in recent years (Hung, Hwang, Lee, \& Su, 2012; Lowrie \& Jorgensen, 2011; Tomte \& Hatlevik, 2011; Yang \& Chen, 2010). 


\section{References}

Alexander, A. (2011). How reliant are college students on smart phones? Retrieved March 13, 2012 from http://ansonalex.com/technology/how-reliant-are-college-students-on-smartphones-infographic/

Amabile, T. M. (1996). Creativity in context: Update to "The Social Psychology of Creativity". Boulder, CO: Westview Press.

Amabile, T. M. (1997a). Entrepreneurial creativity through motivational synergy. Journal of Creativity Behavior, 31(1), 18-26.

Amabile, T. M. (1997b). Motivating creativity in organizations: On doing what you love and loving what you do. California Management Review, 40(1), 39-58.

Antonietti, A. (2000). Enhancing creative analogies in primary school children. North American Journal of Psychology, 2(1), 75-84.

Ayan, J. E., \& Rick, B. (1997). Aha!: 10 ways to free your creative spirit and find your great ideas. New York, NY: Crown Trade.

Baloche, L. (1994). Creativity and cooperation in the elementary music classroom. The Journal of Creative Behavior, 28(4), 255-265.

Bandura, A. (1976). Social Learning Theory. Englewood Cliffs, NJ: Prentice Hall.

Baron, J. A. (2010, September). What is innovation in learning and teaching within higher education? Paper presented at the Education Research Group of Adelaide (ERGA) conference 2010: The Changing Face of Education, Adelaide, Australia.

Bryman, A., \& Cramer D. (1997). Quantitative Data Analysis with SPSS for Windows. Routledge, London.

Buzan, T. (2000). Use your head. London. UK: BBC.

Buzan, T., \& Buzan, B. (2006). The mind map book. Edinburgh Gate, UK: Pearson Education.

Carrier, C. (1998). Employee Creativity and Suggestion Programs: An Empirical Study. Creativity and Innovation Management, 7(2), 62-72.

Carroll, E. A., Latulipe, C., Fung, R., \& Terry, M. (2009, October). Creativity Factor Evaluation: Towards a Standardized Survey Metric for Creativity Support. In Proceedings of ACM Creativity \& Cognition 2009.

Cheng, K. K. W. (2009). The comparative effect on business creativity when web based collaborative learning vs. traditional lecturing instruction. Research in Higher Education Journal, 2. Retrieved from http://jupapadoc.startlogic.com/manuscripts/08115.pdf

Chiu, M. M. (2008). Flowing toward correct contributions during groups' mathematics problem solving: A statistical discourse analysis. Journal of the Learning Sciences, 17(3), 415-463.

Chiu, M. S. (2009). Approaches to the teaching of creative and non-creative mathematical problems. International Journal of Science and Mathematics Education, 7(1), 55-79.

Chu, H. C., Hwang, G. J., Tsai, C. C., \& Tseng, J. C. R. (2010). A two-tier test approach to developing location-aware mobile learning systems for natural science course. Computers \& Education, 55(4), 1618-1627.

Clements, D. H. (1987). Computers and young children: A review of the research. Young Children, 43(1), 34-44.

Clements, D. H. (1991). Enhancement of creativity in computer environments. American Educational Research Journal, 28(1), 173-187.

Cohen, J. (1988). Statistical power analysis for the behavioral sciences (2nd ed.). Hillsdale, NJ: Lawrence Erlbaum.

Csikszentmihalyi, M. (1997). Creativity: Flow and the Psychology of Discovery and Invention. London, UK: Harper Perennial. 
David, F. R. (1986). Fundamentals of strategic management. Columbus: Merrill Pub Co.

Davidson, N., \& O'Leary, P. W. (1990). How cooperative learning can enhance mastery teaching. Educational Leadership, 47(5), 30-40.

de Jesus, H. P., De Souza, F. N., Teixeira-Dias, J. C., \& Watts, M. (2005). Organizing the chemistry of question-based learning: a case study. Research in Science \& Technological Education, 23(2), 179193.

Delgado-Téllez M., \& Pérez Raposo A. (2011, November). Motivating Creativity and Cooperation in Classroom. 4th International Conference of Education, Research and Innovations (ICERI 2011), Madrid, Spain.

Dijk, C., \& Ende, J. (2002). Suggestion systems: transferring employee creativity into practicable ideas. $R$ \& D Management, 32(5), 387-395.

Fishkin, A. S., Johnson, A. S. (1998). Who is creative? Identifying children's creative abilities. Roeper Rev. 21(1), 40-6.

Gallupe R. B., Dennis A. R., Cooper W. H., Valacich J. S., Bastianutti L. M., \& Nunamaker Jr., J. F. (1992). Electronic brainstorming and group size. Academy of Management Journal, 35(2), 350-369.

Garaigordobil, M. (2006). Intervention in creativity with children aged 10 and 11 years: Impact of a play program on verbal and graphic-figural creativity. Creativity Research Journal, 18(3), 329-345.

Gentner, D., Anggoro, F. K., \& Klibanoff, R. S. (2011). Structure mapping and relational language support children's learning of relational categories. Child Development, 82(4), 1173-1188.

Glor, E. D. (1998). What do we know about enhancing creativity and innovation? A review of literature. The Innovation Journal: The Public Sector Innovation Journal, 3(1). Retrieved from http://www.innovation.cc/peer-reviewed/creativ7.htm

Guilford, J. P. (1957). Creative abilities in the arts. Psychological Review, 64(2), 110-118.

Hung, P. H., Hwang, G. J., Lee, Y. H., \& Su, I. H. (2012). A cognitive component analysis approach for developing game-based spatial learning tools. Computers \& Education. doi: 10.1016/j.compedu.2012.03.018.

Hwang, G. J., \& Chang, H. F. (2011). A formative assessment-based mobile learning approach to improving the learning attitudes and achievements of students. Computers \& Education, 56(4), 1023 1031.

Hwang, G. J., Shi Y. R., \& Chu H. C. (2011). A concept map approach to developing collaborative Mindtools for context-aware ubiquitous learning. British Journal of Educational Technology, 42(5), 778-789.

Hwang, G. J., Wu, P. H., \& Ke, H. R. (2011). An interactive concept map approach to supporting mobile learning activities for natural science courses. Computers \& Education, 57(4), 2272-2280.

Isaksen, S. G., \& Parnes, S. J. (1985). Curriculum planning for creative thinking and problem solving. The Journal of Creative Behavior, 19(1), 1-29.

Ismail, M. N., Ngah, N. A., \& Umar, I. N. (2010). The effects of mind mapping with cooperative learning on programming performance, problem solving skill and metacognitive knowledge among computer science students. Journal of Educational Computing Research, 42(1), 35-61.

Jonassen, D.H. (1996). Computers in the classroom: Mindtools for critical thinking. Columbus, $\mathrm{OH}$ : Merrill/Prentice-Hall.

Kao, G. Y.-M., Lin, S. S. J., \& Sun, C. T. (2008). Breaking concept boundaries to enhance creative potential: using integrated concept maps for conceptual self-awareness. Computers \& Education, 51(4), 1718-1728.

Ke, C. E. (2004). Application of creative thinking model based on metacognitive theory in teaching. Curriculum \& Instruction Quarterly, 7(1), 15-30. 
Klein, R. R., \& Letaief, R. (2005, July). CSCL for NGO's cross cultural virtual teams in Africa: an Ethiopian children advocacy case study against exclusion and toward facilitation of expression, innovation and creativity. Paper presented at the Fifth IEEE International Conference on Advanced Learning Technologies (ICALT 2005), Kaohsiung, Taiwan.

Komarik, E., \& Brutenicova, E. (2003). Effect of creativity training on preschool children. Studia Psychologica, 45(1), 37-42.

Kurtzberg, R. L., \& Reale, A. (1999). Using Torrance's problem identification techniques to increase fluency and flexibility in the classroom. Journal of Creative Behavior, 33, 202-207.

LaBarre, P. (1996). Lighten up! Blurring the line between fun and work not only humanizes organizations, but strengthens the bottom line. Industry Week, 245(3), 53-67.

Lanchwathanakorn, C. (2011). Development of a mindtool-based scaffolded reading instruction system with evidence-based intervention to enhance critical reading and critical thinking skills of sixth grade students with reading difficulties. In S. Barton et al. (Eds.), Proceedings of Global Learn Asia Pacific 2011 (pp. 1982-1986). AACE.

Liu, E. Z. F., Lin, C. H., Jian, P. H., \& Liou, P. Y. (2012). The dynamics of motivation and learning strategy in a creativity-supporting learning environment in higher education. The Turkish Online Journal of Educational Technology, 11(1), 172-180.

Liu, P. L., Chen, C. J., \& Chang, Y. J. (2010). Effects of a computer-assisted concept mapping learning strategy on EFL college students' English reading comprehension. Computers \& Education, 54(2), 436-445.

Looi, C. K., Seow, P., Zhang, B., So, H. J., Chen, W., \& Wong, L. H. (2010). Leveraging mobile technology for sustainable seamless learning: a research agenda. British Journal of Educational Technology, 41(2), 154-169.

Lowrie, T., \& Jorgensen, R. (2011). Gender differences in students' mathematics game playing. Computers \& Education, 57(4), 2244-2248.

Mayer, R. E. (1999). Fifty years of creativity research. In R. J. Sternberg (Ed.), Handbook of Creativity (pp. 449-460). New York: Cambridge.

McCrae, \& Robert,R. R. (1987). Creativity, divergent thinking, and openness to experience. Journal of Personality and Social Psychology, 52(6), 1258-1265.

Miner, J. T., \& Miner, L. E. (2008). Proposal Planning \& Writing (4th ed.). Santa Barbara, CA: ABCCLIO.

Ministry of Education Republic Taiwan, Republic of China (R.O.C) (2003). White Paper on Creative Education - Establishing a Republic of Creativity (R.O.C.) for Taiwan. Taipei, TW: Ministry of Education Taiwan.

Mitnik, R., Recabarren, M., Nussbaum, M., \& Soto, A. (2009). Collaborative robotic instruction: A graph teaching experience. Computers \& Education, 53(2), 330-342.

Parker, K. R., \& Chao, J. T. (2007). Wiki as a teaching tool. Interdisciplinary Journal of Knowledge and Learning Objects, 3, 57-72.

Parnes, S. J. (1967). Creative Behavior Guidebook. New York, NY: Scribners.

Peters, R. W., \& Torrance, E. P. (1972). Dyadic interaction of preschool children and performance on a construction task. Psychological Reports, 30, 747-750.

Putman, V. L., \& Paulus, P. B. (2009). Brainstorming, brainstorming rules and decision making. The Journal of Creative Behavior, 43(1), 29-40.

Robinson, K. (2006). Do schools kill creativity? Paper presented at the TED2006 conference, Monterey, CA.

Robinson, K. (2011). Out of our minds: learning to be creative (2nd ed.). Oxford, UK: Capstone.

Sawyer, R. K. (2006). Educating for innovation. Thinking Skills and Creativity, 1(1), 41-48. 
Shaw, R. S. (2010). A study of learning performance of e-learning materials design with knowledge maps. Computers \& Education, 54(1), 253-264.

Skemp, R. R. (1979). Intelligence, learning, and action: A foundation for theory and practice in education. New York, NY: Wiley.

Sternberg, R. J., \& Lubart, T. I. (1999). The concept of creativity: Prospects and paradigms. In R. J. Sternberg (ED.), Handbook of creativity (pp. 3-15). San Diego, CA: Academic Press.

Thousand, J. S., Villa R. A., \& Nevin A. I. (2002). Creativity and Collaborative Learning: The Practical Guide to Empowering Students and Teachers (2nd ed.). Baltimore, MD: Brookes Publishing Company

Tidd, J., Bessant, J., \& Pavitt, K. (1997). Managing innovation: integrating technological, market, and organizational change. New York: John Wiley.

Tomte, C., \& Hatlevik, O. E. (2011). Gender-differences in Self-efficacy ICT related to various ICT-user profiles in Finland and Norway. How do self-efficacy, gender and ICT-user profiles relate to findings from PISA 2006. Computers \& Education, 57(1), 1416-1424.

Torrance, E. P. (1970). Influence of dyadic interaction on creative functioning. Psychological Reports, 26, 391-394.

Torrance, E. P. (1971). Stimulation, enjoyment and originality in dyadic creativity. Journal of Educational Psychology, 62, 45-48.

Turnbull, M., Littlejohn, A., \& Allan, M. (2010). Creativity and collaborative learning and teaching strategies in the design disciplines. Industry and Higher Education, 24(2), 127-133.

Uzunboylu, H., Cavus, N., \& Ercag, E. (2009). Using mobile learning to increase environmental awareness. Computers \& Education, 52(2), 381-389.

Ward, D. (2011). Writing grant proposals that win (4th ed.). Boston, MA: Jones \& Bartlett Publishers.

Wright, C., \& Fesler, L. L. (1990). Nurturing creative potentials: A model early childhood program. In C. W. Taylor (Ed.), Expanding awareness of creative potentials worldwide (pp. 138-142). Salt Lake, UT: Braib Talent-powers.

Wycoff, J., \& Richardson, T. (1995). Transformation Thinking. New York, NY: Berkley Books.

Yang, H. L., \& Cheng, H. H. (2010). Creativity of student information system projects: From the perspective of network embeddedness. Computers \& Education, 54(1), 209-221.

Yang, J. C., \& Chen, S. Y. (2010). Effects of gender differences and spatial abilities within a digital pentominoes game. Computers \& Education, 55(3), 1220-1233.

Yeh, Y. C., \& Wu, J. J. (2006). The cognitive processes of pupils' technological creativity. Creativity Research Journal, 18, 213-227.

Corresponding author: Gwo-Jen Hwang, gjhwang.academic@gmail.com

Australasian Journal of Educational Technology (C) 2013.

Please cite as: Wu, C.-H., Hwang, G.-J., Kuo, F.-R., \& Huang, I. (2013). A mindtool-based collaborative learning approach to enhancing students' innovative performance in management courses.

Australasian Journal of Educational Technology. 29(1), 128-142. 